\title{
CAN RELICT CREVASSE PLUMES ON ANTARCTIC ICE SHELVES REVEAL A HISTORY OF ICE-STREAM FLUCTUATION?
}

\author{
by
}

\author{
D.R. MacAyeal
}

(University of Chicago, Department of the Geophysical Sciences, 5734 S. Ellis Avenue, Chicago, IL 60637, U.S.A.)

\section{R.A. Bindschadler}

(Oceans and Ice Branch, Code 671, NASA / Goddard Space Flight Center, Greenbelt, MD 20771, U.S.A.)

$$
\text { K.C. Jezek }
$$

(U.S. Army CRREL, 72 Lyme Road, and Thayer School of Engineering, Dartmouth College, Hanover, NH 03755, U.S.A.)

and

\section{S. Shabtaie}

(University of Wisconsin-Madison, Geophysical and Polar Research Center,

1215 W. Dayton Street, Madison, WI 53706-1692, U.S.A.)

\section{ABSTRACT}

Configurations of relict surface-crevasse bands and medial moraines that emanate from the shear margins of ice streams are simulated, using a numerical model of an ideal rectangular ice shelf to determine their potential for recording a past ice-stream discharge chronology.

\section{INTRODUCTION}

Radar surveys of the Ross and Filchner-Ronne ice shelves reveal englacial moraine and relict crevasse bands (together referred to as plumes) that emanate from the margins of ice streams, outlet glaciers and ice rises (Doake 1981, Jezek 1984, Crabtree and Doake 1986, Shabtaie and Bentley 1987). As shown for Ross Ice Shelf in Figure 1,

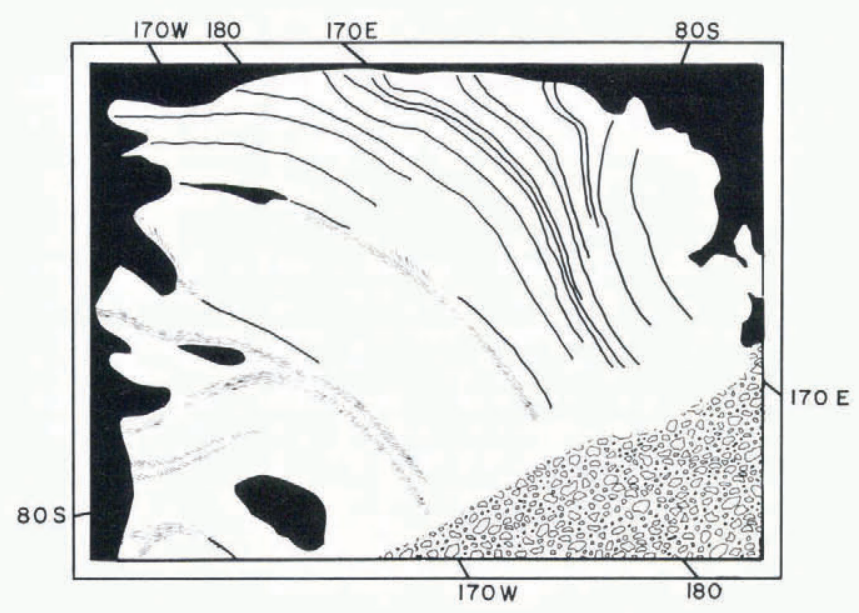

Fig. 1. Medial moraines (thin lines) and relict surface-crevasse bands (heavy lines) observed by radar surveys of Ross Ice Shelf (adapted from Jezek (1984) and Shabtaie and Bentley (1987)). Black areas denote grounded-ice sheet or ice-free mountains. these plumes delimit effluent from individual source glaciers that coalesce within the main body of the ice shelf. Although it is common to call these features flow lines (imaginary curves in the horizontal plane that at every point are tangent to the local horizontal flow vectors) or particle trajectories, they are neither. A plume (also called streak line) is defined as the locus of all fluid elements that at some earlier time passed through a given point in space (Batchelor 1967). Relict crevasse bands and moraines are thus analogous to the visible line that is produced when dye or some other marking material is discharged slowly at a fixed point in a moving fluid.

Recent field studies of the West Antarctic ice streams suggest that their discharge into the Ross and Filchner-Ronne ice shelves can fluctuate rapidly (Shabtaie and Bentley 1987). It is thus natural to ask whether plumes that extend down-stream of potentially variable ice streams record a history of past ice-stream activity. We investigate the effect of ice-stream discharge transience on debris-plume trajectories by simulating the evolution of several imaginary plumes in a time-dependent finite-element model of an ideal, rectangular ice shelf. This ice shelf, shown in Figure 2, has similar dimensions to that part of Ross Ice Shelf which contains effluent from ice streams B and C. Two imaginary ice streams which have prescribed time-dependent discharge are assumed to flow into the ideal ice shelf. Although we intend eventually to simulate plume evolution in the natural geometries of the Ross and Filchner-Ronne ice shelves (see Lange and MacAyeal 1988, this volume), we restrict our attention here to the ideal geometry because it affords greater flexibility and ease in the prescription of ice-stream forcing and model boundary conditions.

\section{MODEL DESCRIPTION}

The finite-element model used to simulate ice-shelf thickness, velocity and plume configuration as functions of time is described by MacAyeal (1987; see also Lange and MacAyeal 1988, this volume). In brief, the ice-thickness distribution is advanced through discrete time steps, using the mass-continuity equation, an implicit time-stepping 
1.

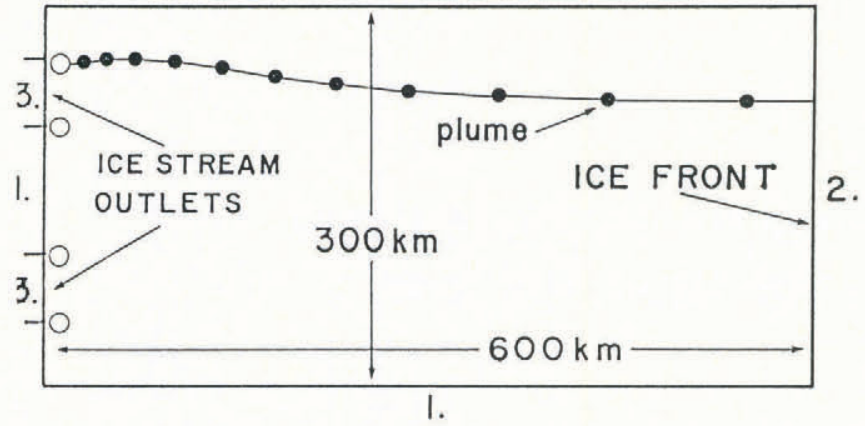

Fig. 2. The ideal ice shelf used in the model. Finite-element mesh resolution is $20 \mathrm{~km} \times 10 \mathrm{~km}$ (along the longitudinal and transverse axes respectively). Boundary conditions required by the model are indicated by numbers: 1. no slip, no flux along sides, rear margin or in corners; 2. normal stress equal to sea-water pressure (integrated over vertical extent of ice front), no tangential stress, ice-volume flux specified to allow free advection through the ice front (iceberg-calving rate equal to velocity perpendicular to ice front); 3 . velocity and volume flux specified as functions of time (both specified as constant across the ice-stream outlets, and to be perpendicular to grounding lines; variations in velocity are assumed to be in phase with variations in flux). Englacial debris and relict crevasse plumes are modeled by imaginary markers that drift freely with the ice-shelf flow. Families of markers (solid circles) that are released sequentially in time from the same starting locations (open circles) form the plume trajectories. In our simulations, marker density is greater than that shown in the figure.

scheme (for stability), a finite-element representation of horizontal mass-transport divergence, prescribed surface and basal accumulation rates $(0.1$ and $0.0 \mathrm{~m} / \mathrm{a}$ ice equivalent respectively) and appropriate mass-flux boundary conditions (summarized in Table I and Fig. 2). At each time step, the flow field is generated from the ice-thickness distribution, the stress-equilibrium equations, Glen's flow law and appropriate stress boundary conditions, using the finite-element method. This flow field is then used in the mass-continuity equation in order to advance the ice thickness through the next time step. For simplicity, and to avoid the computational difficulty of modeling ice-shelf temperature, we assume the ideal ice shelf to be isothermal (giving an ice-stiffness parameter of $1.6 \times 10^{8} \mathrm{~Pa} \mathrm{~s}^{1 / 3}$; for

\section{TABLE I. ICE-STREAM FORCING SCENARIOS}

$\begin{array}{cccc}\begin{array}{c}\text { Run } \\ \text { no. }\end{array} & \text { Description } & \begin{array}{c}\text { Period } \\ \text { (a) }\end{array} & \begin{array}{c}\text { Phase shift } \\ \text { (rad) }\end{array} \\ 1 & \text { switch-off } & - & - \\ 2 & \text { periodic } & 3000 & \pi \\ 3 & \text { periodic } & 3000 & \pi / 2 \\ 4 & \text { periodic } & 1500 & \pi \\ 5 & \text { periodic } & 500 & \pi\end{array}$

Notes: Prescribed velocity and volume flux for run 1 were $500 \mathrm{~m} / \mathrm{a}$ and $20 \mathrm{~km}^{3} / \mathrm{a}$ respectively for the remaining active ice stream. Prescribed velocity and volume flux for runs 2-5 were sinusoidal in time and ranged from $0-1000 \mathrm{~m} / \mathrm{a}$ and from $0-40 \mathrm{~km}^{3} / \mathrm{a}$ respectively. Phase shift in runs $2-5$ refers to the time lag between maximum flux of the upper ice stream (in the figures) and maximum flux of the lower ice stream. Velocity and flux for a given ice stream are prescribed to be in phase with each other. terminology refer to MacAyeal (1987)) and to have constant density $\left(917 \mathrm{~kg} / \mathrm{m}^{3}\right)$. Variable ice-stream discharge is accommodated by prescribing the time-dependent velocity and volume flux uniformly along the ice-stream grounding lines (Fig. 2). Initial conditions and ice-stream forcing scenarios of the five simulations conducted in this study are summarized in Table I.

Plumes are simulated by imaginary markers that drift passively with the ice-shelf flow, as shown in Figure 2. At each time step, new markers are released at fixed starting positions that correspond to the four shear zones at the margins of the two ice-stream outlets (these positions are offset $5 \mathrm{~km}$ from the edges of the ice streams in accord with the observations of Shabtaie and Bentley (1987)). At arbitrary instants in time the plumes are determined by the curves that connect sequentially released markers which emanate from each of the four starting positions.

\section{IMPULSIVE STAGNATION}

We simulated the adjustment between two steady-state configurations that were caused by sudden stagnation of one of the two ice streams (run 1 in Table I). This experiment illustrates the time required for plume configurations to equilibrate with new forcing conditions, and is fashioned after the supposed reduction of Ice Stream C's discharge into Ross Ice Shelf approximately 250 years ago (Rose 1979 , Shabtaie and Bentley 1987). The initial ice-shelf configuration was in steady state, with equal discharge $\left(500 \mathrm{~m} / \mathrm{a}, 20 \mathrm{~km}^{3} / \mathrm{a}\right)$ from the two ice streams. After one ice stream was eliminated (the other was unchanged), the model was run until a new steady-state equilibrium was achieved (approximately 3000 a). Initial and final debris-plume configurations are shown in Figure 3.

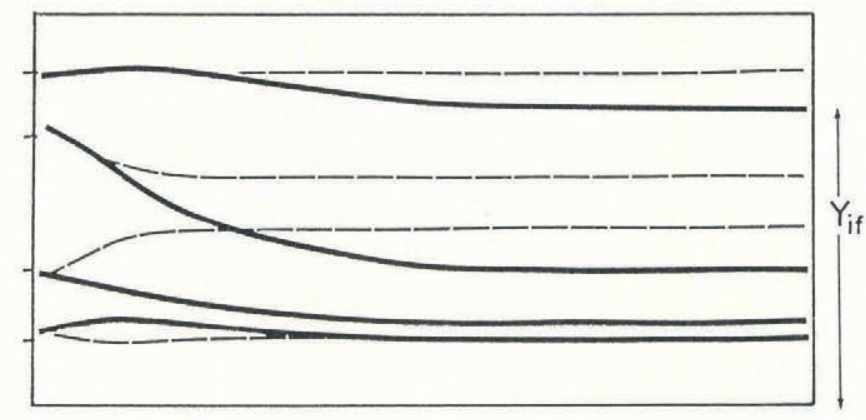

Fig. 3. Initial (thin broken lines) and final (heavy lines) plume trajectories associated with adjustment to sudden stagnation of the lower ice stream (run 1), plotted on the map of the ideal ice shelf shown in Figure 2. $y_{\text {if }}$ is the transverse coordinate of the point where a given plume crosses the ice front. The two plumes originating at the margins of the lower, inactive ice stream are shown despite the probability that the process by which they originate may cease once the ice stream stops.

Transient adjustment to the sudden cessation of ice-stream discharge is monitored by measuring two time-dependent parameters, $y_{\mathrm{if}}(t)$ and $d(t)$, for each plume. As shown in Figure $3, y_{\mathrm{if}}(t)$ is the transverse horizontal coordinate of the point where each plume crosses the ice front. $d(t)$ is the length-averaged angular deviation between the tangent to the plume and the local velocity vector:

$$
d(t)=\frac{1}{L(t)} \int_{\Gamma} \cos ^{-1}\left[\frac{|s \cdot u|}{|s||u|}\right] \mathrm{d} \lambda
$$

Here $L(t)$ is the length of the plume (a function of time $t$ ), $\Gamma$ is the path the plume traces through the horizontal plane parameterized by $\mathrm{d} \lambda, s$ is the local tangent vector to $\mathrm{r}$, and $u$ is the horizontal ice-shelf velocity at points along $r$. 


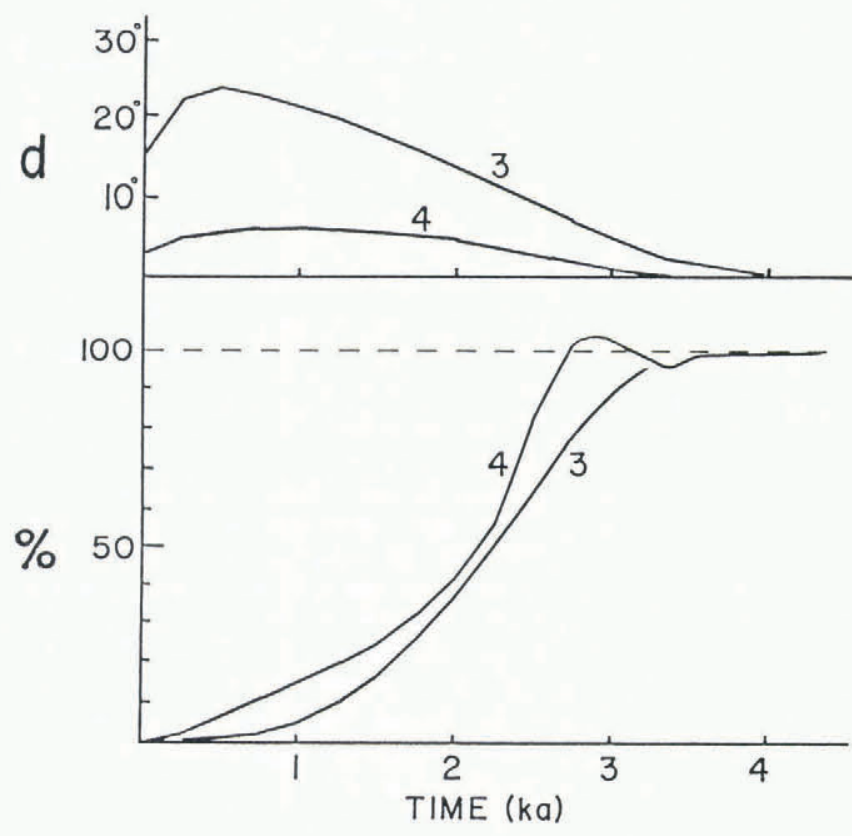

Fig. 4. Adjustment of two plumes that limit effluent from the remaining active ice stream (the upper two trajectories in Figure 3; "3" is closest to the center of the ice shelf and "4" is closest to the ice-shelf margin). The upper graph displays $d(t)$ (in degrees) for each of the two plumes. The lower graph displays the cumulative change in $y_{\text {if }}$ expressed as a percentage of the total change in $y_{\text {if }}$.

As shown in Figures 3 and $4, y_{\text {if }}(t)$ for the two plumes that emanate from the remaining active ice stream equilibrate in approximately $3000 \mathrm{a}$. The greater part of this equilibration occurs after $1500 \mathrm{a}$, which is the average residence time of ice parcels within the ice shelf. In contrast to $y_{\text {iff }}(t), d(t)$ for the two active debris tracks reach their maximum during the initial $500 \mathrm{a}$, and then slowly decay back to zero. This result suggests that angular deflection of the plumes from the instantaneous flow lines is a more immediate consequence of ice-stream transience. Although we measure this deflection in terms of its length average $d(t)$, it may be more practical to observe this deflection at discreet points along the plume.

\section{PERIODIC ICE-STREAM FORCING}

Plume sensitivity to ice-stream discharge time-scales and phase relationships is examined in runs $2-5$, where prescribed discharge fluctuations are periodic (Table I). Experience with run 1 suggested that, for the ideal ice shelf we model, time-scales in the range of 500 to 3000 a would produce the greatest range of plume variability. If forced at time-scales longer than $3000 \mathrm{a}$, the plumes would evolve quasi-statically with the instantaneous ice-stream forcing. If forced at time-scales less than $500 \mathrm{a}$, the plumes would adopt configurations reflecting the time-mean state of ice-stream forcing. This lower time-scale limitation is required partly by Nature and partly by the coarse spatial resolution of the finite-element model.

Each simulation was run for eight complete cycles of variation, using a time step of one-fortieth of the forcing period. The plumes were updated every one-sixteenhundredth of the forcing period (less than $3.5 \mathrm{a}$, for accuracy in representing marker drift). During the first seven cycles, effects induced by the initial conditions (specified to be in steady state, with equal, steady discharge from both ice streams) were dissipated. By the eighth cycle, the simulated plumes, ice-shelf thickness and ice-shelf velocity were oscillating periodically in a manner whereby each subsequent cycle was a repetition of the previous cycle.

Envelopes that demarcate instantaneous plume configurations (shown in Fig. 5) provide a means of
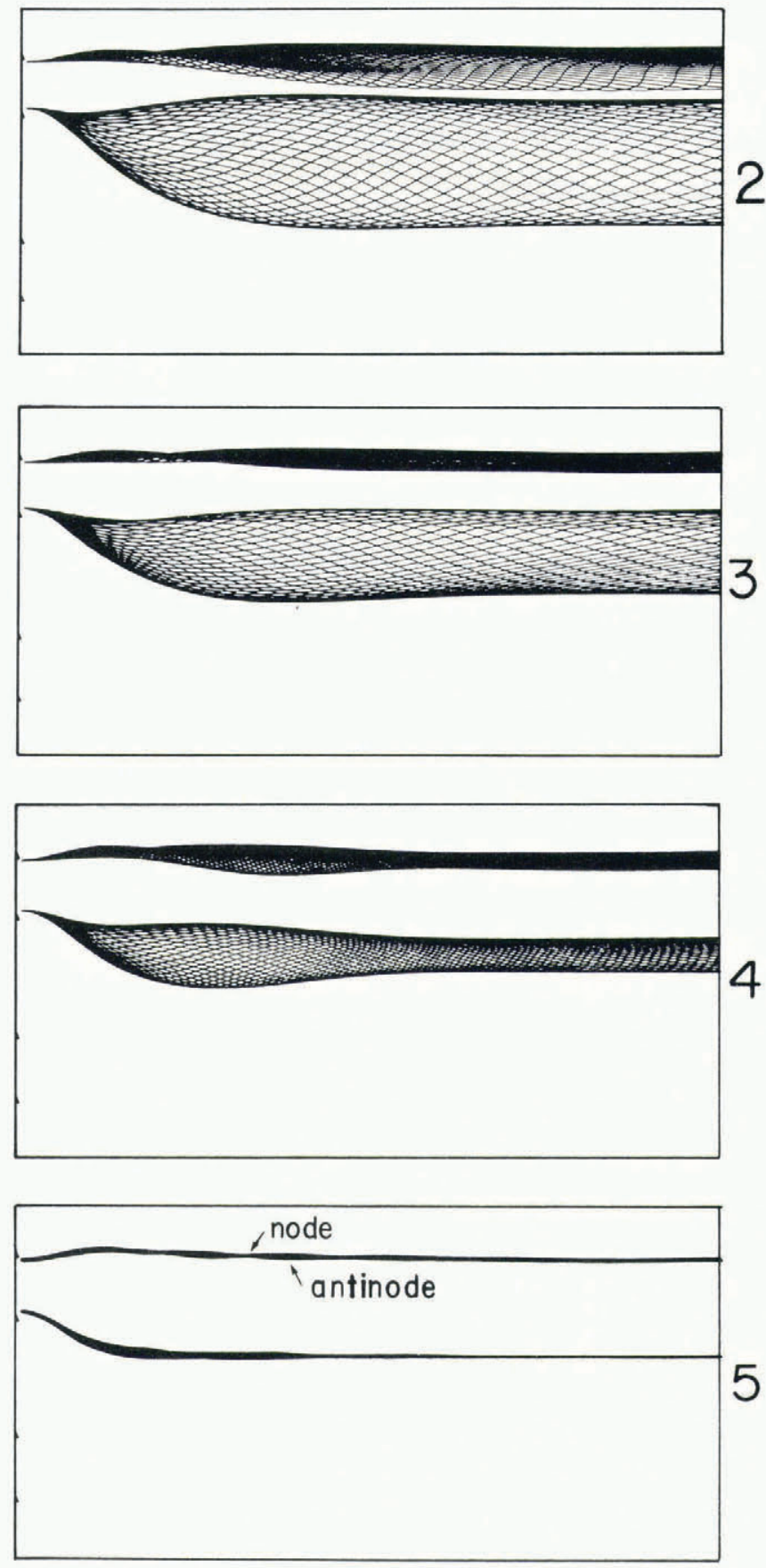

Fig. 5. Plume envelopes for periodic ice-stream discharge (the run number is indicated on the right). Envelopes are constructed by superimposing instantaneous plume trajectories at intervals of one-fortieth of the forcing period (individual lines within each envelope are not intended to be interpreted). For clarity, envelopes associated with the two lower plumes are not shown.

comparing the results of runs 2-5. Low frequencies are seen to produce greater transverse deviations than high frequencies. At high frequency, wave-like patterns of nodes and antinodes appear in the envelopes. These patterns form when the plume contains markers that were released during successive cycles of ice-stream discharge.

Plume evolution throughout a cycle of ice-stream forcing is controlled by two factors: (i) the transverse component of the instantaneous flow near the ice-stream outlets, and (ii) transverse shear in the longitudinal velocity component. The first factor produces the net transverse displacement of any given part of the plume. As shown in Figure 6, deviation between the plume track and the instantaneous flow lines is smallest near the ice-stream outlets. This is also where the transverse deviations of the 

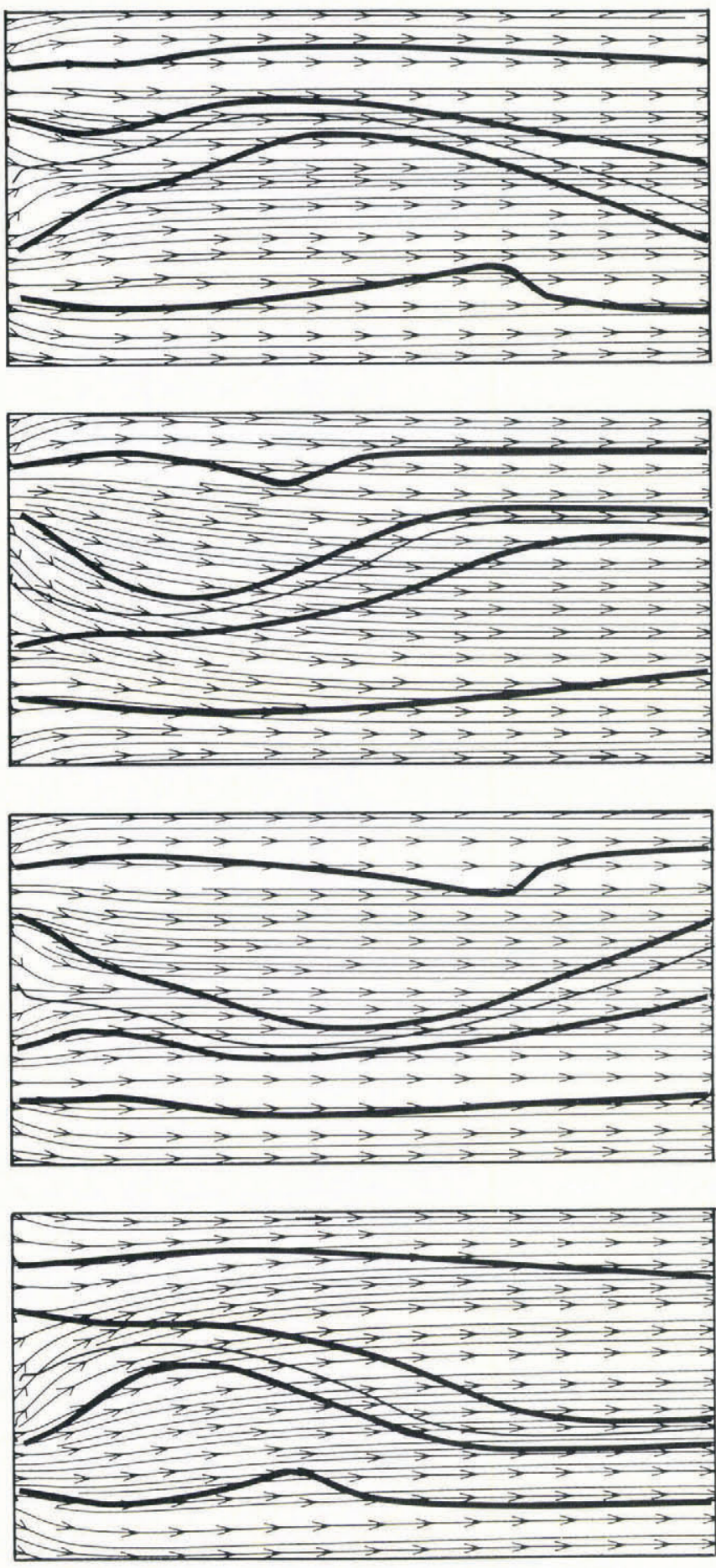

Fig. 6. Instantaneous configurations of flow lines (thin lines with arrows) and plume trajectories (thick lines) at time intervals corresponding to forcing phases of $0, \pi / 2, \pi$, and $3 \pi / 4$ (top to bottom respectively) throughout a given 3000 year cycle of ice-stream discharge variation (run 2 in Table I). Each image is separated by 750 year intervals. A fifth plume, originating at the head of the ice shelf, midway between the two outlets, is shown as a moderately heavy line.

instantaneous flow lines are greatest. Down-stream, where plumes and flow lines deviate most from each other, the flow lines are aligned with the longitudinal axis and can no longer alter the transverse position of the plume markers. Transverse displacements along a given plume track at an instant in time are thus determined by former conditions near the outlets.

The second factor governing plume evolution is transverse shear. As shown in Figure 7 , small transverse bumps in the plumes (visible near the ice-stream outlets)

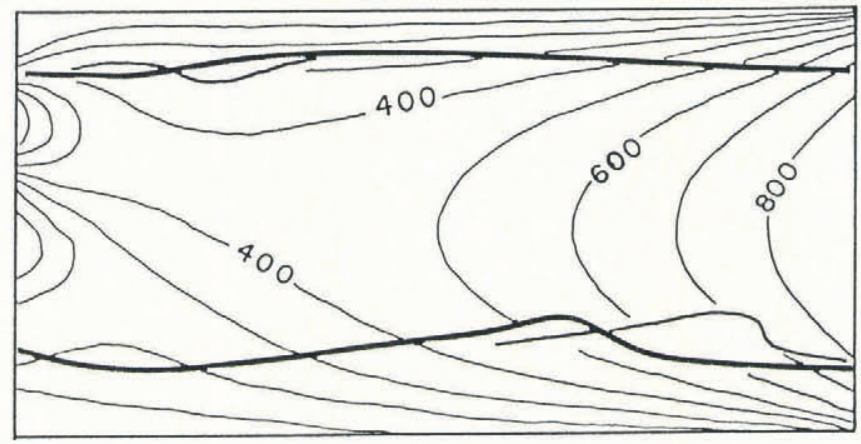

Fig. 7. Small transverse bumps in plume trajectories are amplified and folded by the transverse gradient of the velocity. This amplification is demonstrated above by superimposing the instantaneous plume trajectories sampled at times separated by an interval of 300 years, or onetenth of the forcing period (run 2 in Table I). The initial plume configuration is shown by the heavy line, the relevant part of the second trajectory is shown by the lighter line. The velocity magnitude at the intermediate time is contoured in $\mathrm{m} / \mathrm{a}$.

are amplified and eventually folded, as they progress down-stream, by transverse gradients in longitudinal velocity. Such folds could easily be misinterpreted as parts of several parallel plumes if they were sampled by radar flights in an inappropriate manner.

\section{PLUME-DATA INVERSION}

Plume trajectories measured at an instant in time can be inverted to obtain information such as: (i) the time-scale of ice-stream variability, (ii) the synchronization between neighboring ice streams, and (iii) the chronology of past ice-stream volume flux. Visual comparison of measured plume trajectories and ice-shelf thickness distribution can indicate qualitatively whether a given ice stream is accelerating or decelerating, and over what time-scale such trends have prevailed. A quantitative estimate of discharge through a given ice-stream outlet during a given time interval can be obtained by: (i) identifying the distorted map image of this discharge within the ice shelf down-stream of the outlet, and (ii) estimating surface and basal ice-volume that has been added to (or removed from) this map image since the time it entered the ice shelf.

This quantitative estimate can be accomplished by using observed plume trajectories, if the elapsed time of residence within the ice shelf (age) can be determined as a function of plume length. In the case of plumes composed of relict surface crevasses, this age can be measured geochemically (for example, by counting annual oxygen-isotope layers above the depth of radar-scattering horizons). Surface and basal accumulations on the plan image of this discharge can be determined from the depth at which the relict surface crevasses are buried and from internal brine horizons. Losses by surface or basal ablation cannot be measured directly and thus introduce uncertainty.

As a demonstration, we estimate an ice-stream discharge chronology for the two model ice streams, using model data (sampled at a single time step) as a substitute for actual field data. The estimated location, configuration and volume of ice discharged during sequential 150 year intervals of run 2 are shown in Figure 8 . The approximate map image of the ice discharged during each interval is represented as a block bounded transversely by plumes and longitudinally by line segments that join markers of the same age on each plume. The line segments that cross the ice-stream effluent and define the contact between blocks of sequentially discharged ice are approximations to the real contacts. In reality, these contacts can be severely distorted by transverse velocity gradients. Ice volume that has accumulated since each block entered the ice shelf is estimated by the depth at which plume markers (assumed to be relict surface crevasses) are buried (this quantity is simulated along with age and position). The accumulation is 

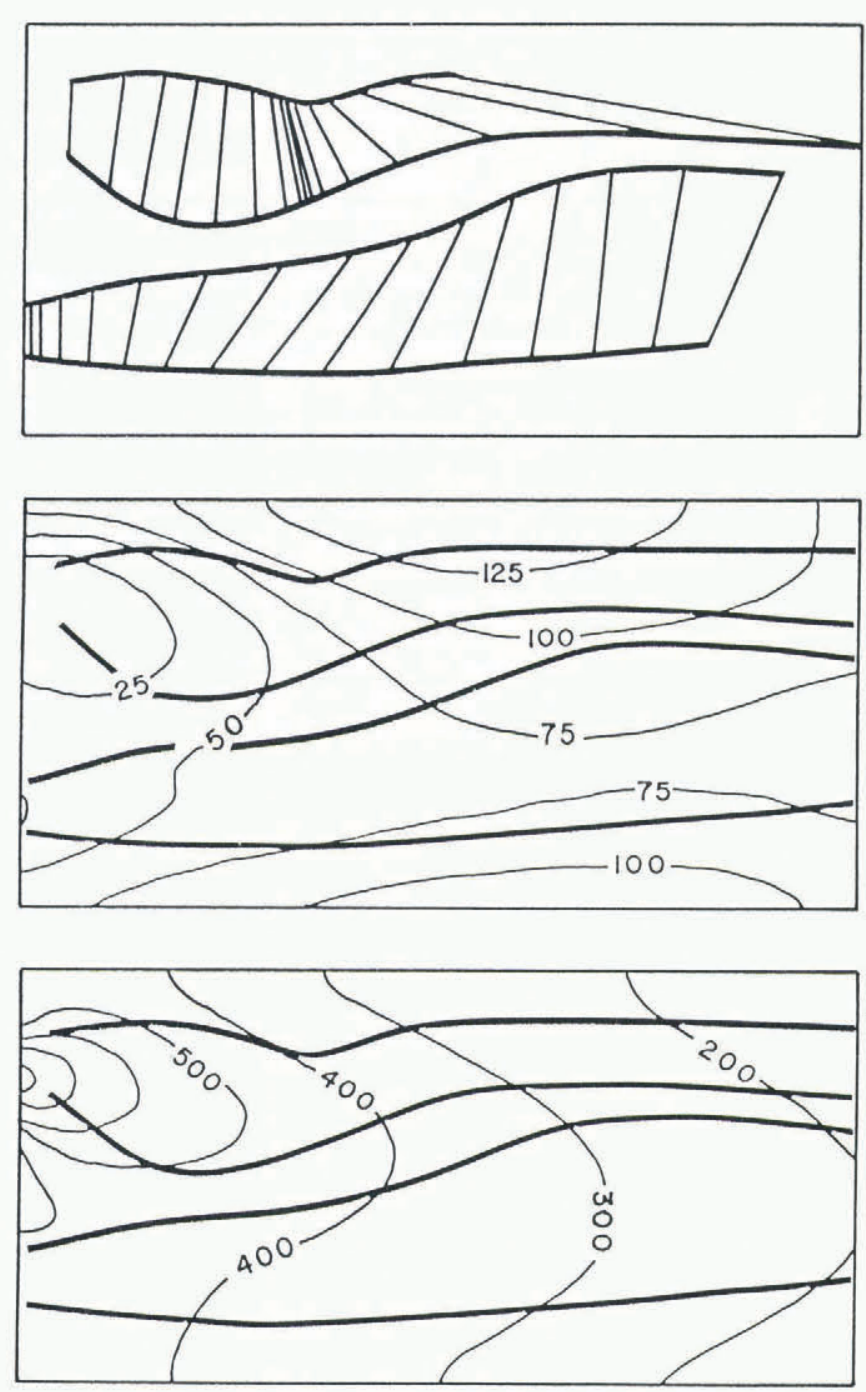

Fig. 8. Synthetic field data derived from the model, sampled at an instant in time when the lower ice stream (referred to as C in Fig. 9) was stagnant and the upper ice stream (B in Fig. 9) was near maximum discharge (data derived from run 2 in Table I). (top) Estimated map configurations of ice volumes discharged during sequential 150 year time intervals. (middle) Thickness of ice derived from snow accumulation at a fixed rate of $0.1 \mathrm{~m} / \mathrm{a}$ on the ice shelf alone (contoured in meters). (bottom) Thickness of ice derived from ice-stream discharge alone (contoured in meters).

subtracted from the total volume of each block (assumed to have been determined from radar data), to give an estimate of the average ice-stream volume flux during the particular time interval in which the block was discharged.

This estimated ice-volume flux chronology is compared with the known flux that was used to force the model in Figure 9. The estimated chronology reproduces the pattern and time-scales of discharge maxima and minima, but underestimates the magnitude. Error in estimating the magnitude of previous discharge is partly due to contact distortion between sequentially released blocks (which reduces the estimated flux by approximately $50 \%$ ) and partly due to artificial limitations imposed by the finite-element representation of ice-shelf thickness evolution. Low spatial resolution of the finite-element grid $(10 \mathrm{~km} \times 20 \mathrm{~km})$, and the implicit time-stepping scheme, cause artificial diffusion of ice across the lateral boundaries of the ice-stream effluent (the plumes that define these boundaries are simulated more precisely than is the ice thickness contained between them). Had we used higher spatial and temporal resolution in our model, our technique for estimating past ice-stream discharge chronology would have been even more convincing than that shown in Figure 9.

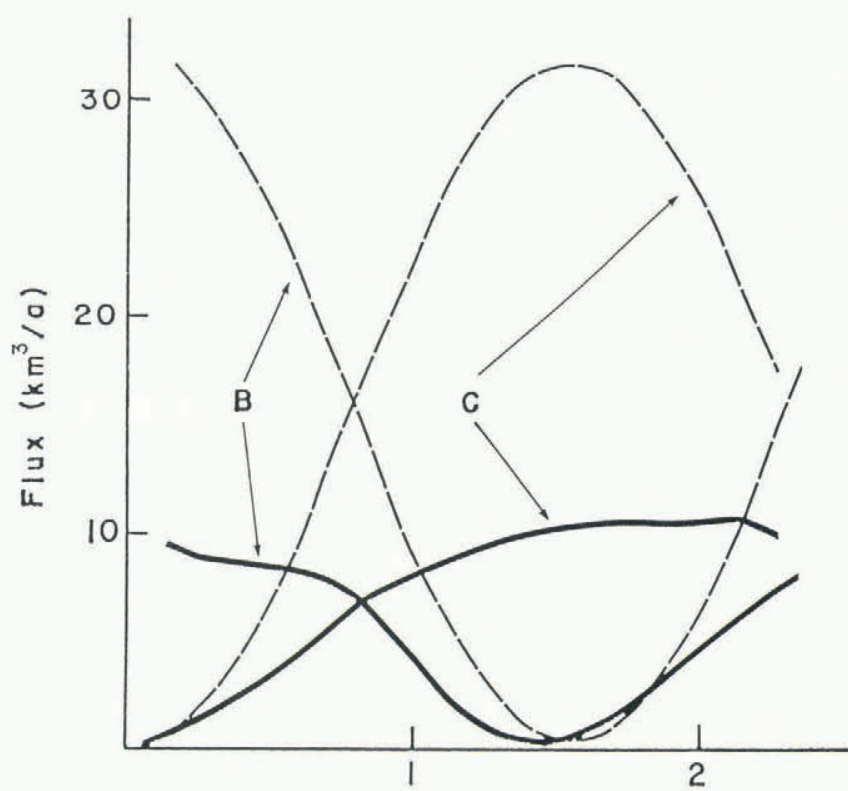

$(k a B P)$

Fig. 9. Heavy lines denote estimated ice-stream discharge chronologies, derived by using model data as a substitute for field data (shown in Fig. 8). Thin broken lines denote actual ice-stream discharge chronologies used for model forcing (the magnitude is reduced to account for the fact that the plumes originate $5 \mathrm{~km}$ inboard of the edges of the ice-stream outlets). Ice streams B and C refer to the upper and lower ice streams shown in Figure 8 (and, by analogy, to ice streams $B$ and $C$ on Ross Ice Shelf).

\section{CONCLUSION}

Experiments performed here demonstrate plume distortions imposed by ice-stream discharge fluctuations, with the appropriate time-scale. These distortions can be measured in three ways: (i) by deviations between plume trajectories and instantaneous flow lines, (ii) by wide transverse excursions of the plumes, and (iii) by kinks and folds in the plume trajectories that are amplified as a result of the transverse velocity gradient. For the typical iceshelf scales represented by our model, deviations between plumes and instantaneous flow lines reach their maximum relatively soon (within 500-750 a) after sudden changes in ice-stream discharge; however, overall equilibration takes significantly longer (approximately 3000 a). This suggests that deviations between plumes and flow lines on Ross Ice Shelf (Fig. 1) that were forced by the supposed stagnation of Ice Stream C approximately 250 years ago (Shabtaie and Bentley 1987) should be approaching their maximum.

Plume response to periodic ice-stream discharge is analogous to a frequency band-pass filter. Very high and very low forcing frequencies produce little sign of plume transience in our simulations. These frequency limits depend on physical factors, including the size and average velocity of the ice shelf (as well as on the spatial resolution of our finite-element model). Discharge fluctuations with periods less than approximately $500 \mathrm{a}$, for example, produce plume distortions over a spatial scale that is too small to be resolved by our model. Fluctuations with periods greater than approximately 3000 a distort plume trajectories quasistatically so that they appear at a given instant to be in steady state with the instantaneous ice-stream discharge.

An ice-stream discharge chronology can be estimated from observed ice-shelf plumes if auxiliary data are collected, including: (i) the elapsed time of residence within the ice shelf as a function of plume length (derived geochemically), (ii) the net volume, derived from surface and basal accumulation on the ice shelf alone (derived from the depth at which relict surface crevasses are buried), and (iii) the configuration of auxiliary plumes (such as suture 
lines or medial moraines) that extend through the middle of the ice-stream outlet rather than to its edges. With these data, it is possible to identify the map image of ice that has been discharged through a given ice stream during a given time interval in the past. To produce a quantitative estimate of past ice-stream volume flux, the volume contained within this map image need only be measured and adjusted for surface and basal accumulation (or ablation) since the time of discharge.

\section{ACKNOWLEDGEMENTS}

This research was supported by the U.S. National Science Foundation (grant DPP-8509451). We thank Manfred A. Lange, Charles R. Bentley and Dean R. Lindstrom for discussion.

\section{REFERENCES}

Batchelor, G.K. 1967. An introduction to fluid dynamics. Cambridge, Cambridge University Press.
Crabtree, R.D., and C.S.M. Doake. 1986. Radio-echo investigations of Ronne Ice Shelf. Ann. Glaciol., 8, 37-41.

Doake, C.S.M. 1981. Tracing particle paths in the Antarctic ice sheet. J. Glaciol., 27(97), 483-486.

Jezek, K.C. 1984. Recent changes in the dynamic condition of the Ross Ice Shelf, Antarctica. J. Geophys. Res., 89(B1), 409-416.

Lange, M.A., and D.R. MacAyeal. 1988. Numerical models of steady-state thickness and basal ice configurations of the central Ronne Ice Shelf, Antarctica. Ann. Glaciol., 11, 64-70.

MacAyeal, D.R. 1987. Ice-shelf back pressure: form drag versus dynamic drag. In Veen, C.J. van der, and J. Oerlemans, eds. Dynamics of the West Antarctic Ice Sheet. Proceedings of a Workshop held in Utrecht, May $6-8$, 1985. Dordrecht, etc., D. Reidel Publishing Company, 141-160.

Rose, K.E. 1979. Characteristics of ice flow in Marie Byrd Land, Antarctica. J. Glaciol., 24(90), 63-75.

Shabtaie, S., and C.R. Bentley. 1987. West Antarctic ice streams draining into the Ross Ice Shelf: configuration and mass balance. J. Geophys. Res., 92(B2), 1311-1336. 